\title{
Un nuevo proyecto de país. El concepto de democracia en los discursos de Néstor Kirchner
}

\author{
A new political project for the country. \\ The concept of democracy in Nestor Kirchner's speeches \\ Florencia Daniela Rispolo \\ Facultad de Humanidades y Ciencias \\ Universidad Nacional del Litoral \\ rispoloflorencia@gmail.com
}

\begin{abstract}
Resumen
En los discursos políticos quedan plasmados los intereses y proyectos de aquellos que son y han sido nuestros representantes, es decir, cada discurso implica una serie de estrategias que han sido seleccionadas por el orador con propósitos preestablecidos. Esto permite suponer que, al analizar los discursos de Néstor Kirchner durante su gestión como presidente de la República Argentina, es posible identificar las nociones de Estado y Democracia que subyacían al proyecto político en cuestión.

Palabras clave: democracia, discurso kirchnerista, proyecto de país, Néstor Kirchner, estrategias discursivas

Abstract

Political speeches capture the interests and projects of those who are and have been our representatives, i.e. each speech implies a series of strategies that are selected by the speaker to achieve pre-established purposes. This allows us to suppose that when analyzing the speeches of Néstor Kirchner, during his term as president of the Argentinian Republic, it was possible to identify the notions of State and Democracy underlying the political project in question. Within this framework, this article aims at investigating, through discursive analysis, how the concept of democracy was constructed during the government of Néstor Kirchner.
\end{abstract}

Keywords: democracy, kirchnerista's speech, national project, Néstor Kirchner, discursive strategies

Fecha de recepción: 04 de septiembre de 2019 | Fecha de aceptación: 04 de diciembre de 2019

Cómo citar este artículo (MLA): Rispolo, Florencia Daniela. "Un nuevo proyecto de país. El concepto de democracia en los discursos de Néstor Kirchner". Estudios del Discurso 6.1 (2020): 32-55. 
Un nuevo proyecto de país

\section{Introducción}

工 a presidencia de Néstor Kirchner fue considerada como un cambio de rumbo venían aplicando hasta el momento (Cheresky; Montero, Memorias discursivas; Montero y Vincent). Fue concebida como una ruptura frente a las prácticas neoliberales, como un proyecto de país nacional y popular, como una nueva forma de gestionar el poder democrático. Sin embargo, lo interesante de ello no es comprobar si estas afirmaciones resultaron veraces o no; por el contrario, resulta más atractivo analizar cómo fueron construidas estas nociones desde el ámbito de la comunicación gubernamental. ${ }^{1}$

Así mismo, en materia de comunicación gubernamental la llegada de Kirchner fue entendida como un quiebre respecto a los gobiernos anteriores (Kitzberger; Vincent). Esta nueva forma de concebir la comunicación de gobierno generó que las alocuciones públicas de Néstor Kirchner se tornaran en un interesante objeto de análisis para diversos autores del ámbito académico. En este sentido, fueron apareciendo estudios relacionados con los condicionamientos a la tarea periodística como producto de la comunicación de gobierno (Amado; Amadeo y Amado), la comunicación política como estrategia de liderazgo presidencial (Vincent), o incluso las disposiciones implementadas respecto a las políticas de comunicación (Califano; Mastrini). Sin embargo, merecen especial atención aquellos estudios que han utilizado diferentes herramientas de la lingüística como instrumentos para conocer y comprender el discurso kirchnerista.

Dentro de este campo de trabajo se encuentran autores como Biglieri y Perelló; Garzón Rogé; Montero, Puesta en escena; Muñoz y Retamozo; y Retamozo queienes estudian, a partir de herramientas lingüísticas, como se construye la identidad kirchnerista. Estos autores ligan las comunicaciones de

\footnotetext{
${ }^{1}$ La comunicación de gobierno es entendida según las definiciones ofrecidas por Riorda (Mitos y políticas; Hacia un modelo de comunicación; Los mitos de gobierno; Gobierno bien pero comunico mal; La comunicación gubernamental) y Canel y Sanders. Sin embargo, por cuestiones de extensión del escrito, de las diferentes comunicaciones emitidas (orales, virtuales, escritas y audiovisuales) sólo serán consideradas aquellas realizadas de forma oral y de fechas específicas.
} 
Florencia Daniela Rispolo

Néstor Kirchner con la dinámica populista que teoriza Laclau. Así, afirman que los discursos poseen dos características propias del populismo: por un lado, instalan una frontera binaria y polarizante que distingue entre un "ellos" y un "nosotros" excluyente; y por otro, asocia ese "nosotros" con la noción de "pueblo", intentando construir una figura hegemónica que encarna y aglutina demandas y discursos circulantes en el espacio social.

Así mismo, existen otros estudios que se alejan de la perspectiva populista, aunque continúan con la idea de "hegemonía discursiva". Un buen ejemplo es el trabajo de Sebastián Barros, quien indaga sobre la emergencia del discurso kirchnerista y los vínculos discursivos con la comunicación sostenida por figuras políticas previas. También es posible mencionar a Fabiana Martínez, quien analiza los tópicos discursivos que persisten a lo largo de todas las gestiones kirchneristas y que configuran lo que considera su "formación discursiva".

Tal como se observa, el discurso de Néstor Kirchner ha sido estudiado desde múltiples y variadas perspectivas, sin embargo, aún existen ciertos conceptos o nociones que no han sido lo suficientemente trabajadas. En este sentido, el artículo pretende indagar, a través del análisis discursivo, cómo fue construida la noción de democracia durante el gobierno de Néstor Kirchner y cómo ésta es asociada a la idea de "nuevo proyecto de gobierno". A partir de este objetivo en el artículo se recortan, de la totalidad de los discursos elaborados por Néstor Kirchner durante su presidencia en el periodo 2003-2007, sólo aquellos que fueron pronunciados en fechas que se consideran de relevancia para el concepto de democracia. ${ }^{2}$ Así, se seleccionan discursos en los cuales se supone que se incluirán reflexiones ideológicas sobre el Estado, la nación y la democracia argentinas. En este sentido, se incluyen alocuciones emitidas en: momentos institucionales, ${ }^{3}$ fechas conmemorativas

${ }^{2}$ Los discursos seleccionados fueron obtenidos del archivo digital con el que cuenta la página oficial de la Casa Rosada (https://www.casarosada.gob.ar/informacion/archivo).

${ }^{3}$ Inicio de mandato (25 de mayo de 2003), inicio de sesiones parlamentarias (años 2004-2007) y fin de mandato (10 de diciembre de 2017). 
sobre la fundación y construcción del Estado argentino, ${ }^{4}$ y discursos que recuerdan periodos funestos para la democracia de nuestro país. ${ }^{5}$

A continuación, y a partir de instrumentos teóricos ofrecidos por diferentes autores del ámbito del análisis del discurso, se identificarán las estrategias utilizadas por el enunciador y se analizará la perspectiva de democracia presente en los textos seleccionados. En este sentido, es importante señalar que se trabajarán las marcas de las operaciones narrativas que aparecen sobre la superficie textual y no los efectos o las recepciones de los discursos escogidos. De este modo, el texto se estructura en cuatro apartados: el primero de ellos, titulado los "Protagonistas de la democracia", que describe los interlocutores a los cuales se dirigían los discursos en cuestión; un segundo subtítulo que se refiere al horizonte utópico al que alude el kirchnerismo, llamado "La reconstrucción de la democracia"; un tercer apartado, denominado "El contenido de la democracia", que repasa la matriz ideológica que estructuró el discurso; y el último, una sección en la cual se analiza estadísticamente la aparición del lexema democracia y se interpretan los valores que se asocian al mismo. El artículo finaliza con las recapitulaciones sobre los temas abordados anteriormente.

\section{Los protagonistas de la democracia}

En primer lugar, es necesario señalar quiénes son los interlocutores a los que se dirigen los discursos seleccionados, es decir, quiénes son los protagonistas de la democracia que se construye en los mismos. Para ello se utilizarán las categorías de prodestinatario, contradestinatario y paradestinatario que propone Eliseo Verón

${ }^{4}$ Discursos emitidos para la conmemoración de la Revolución de Mayo (años 2005, 2006 y 2007), para el Día de la Bandera (2003, 2005 y 2007) y Día la Independencia (años 2004, 2005 y 2007).

${ }^{5}$ Discursos emitidos para el "Día de la Memoria, la Verdad y la Justicia" (años 2004, 2006 y 2007). Cabe aclarar que no fue posible encontrar la totalidad de las alocuciones que se había previsto al idear el corpus discursivo. Sin embargo, esta ausencia no es una decisión intencional de la autora sino producto de la falta de actos oficiales o comunicaciones públicas por parte del exmandatario. 
Florencia Daniela Rispolo

(La palabra adversativa). Si bien cada una de las alocuciones seleccionadas se pronunció en ámbitos diferentes y ante públicos disímiles, existe una definición de los interlocutores que se mantiene constante.

El prodestinatario puede ser identificado en los discursos a partir del colectivo "Nosotros", son aquellos interlocutores que adhieren a los valores del enunciador. En tanto que el paradestinatario es aquel que presenta una posición indecisa, al que generalmente se incorpora a través de la identidad imaginaria de "argentinos y argentinas", "rosarinos y rosarinas", "tucumanos", entre otros. La lógica conduce a pensar que, a menos que sean actos proselitistas, gran parte de los discursos estarían dirigidos a los paradestinatarios a fin de lograr conquistar sus voluntades. Sin embargo, en el discurso kirchnerista esta figura se encuentra ausente o en un segundo plano; mientras que los enunciados dirigidos a los adherentes proporcionan un terreno fértil para que el discurso político conforme y elabore sus propios saberes y creencias, presentándolos como preexistentes (Montero, Puesta en escena).

Por su parte, los destinatarios negativos o contradestinatarios son aquellos a los que se señala como quienes han atentado contra los intereses de todos los argentinos, aquellos que han implantado modelos que protegen intereses corporativos y privados, los enemigos de la patria. Ejemplo de ello es el siguiente fragmento:

El modelo de concentración económica, señoreo de los intereses especiales, corrupción hasta límites inimaginables, destrucción del sistema productivo y de la actividad industrial, elevada exclusión social, cimentado en un impresionante endeudamiento, demostró con toda su crudeza la carencia de propia sustentabilidad y cayó estrepitosamente, destruyendo la legitimidad de las instituciones y desarticulando la legalidad y la cohesión social propias de un país normal. (Kirchner, o1 de marzo de 2004)

De este modo, el discurso rechaza y se aparta de los actos llevados adelante por una dirigencia a la que se define como corrupta, que gestiona intereses de privados y que atenta contra los intereses del pueblo.

El discurso kirchnerista se construye sobre la reafirmación de sus adherentes, a los que presenta como parte del cambio; es decir, como los protagonistas de la democracia, aquellos argentinos que abogan por el cambio y que han sufrido los embates de una clase política que prioriza el beneficio individual. Así, el expresidente 
se enfrenta a un contradestinatario al que define como protagonista de la debacle del Estado, como el enemigo de la renovada democracia que se pretende instalar. Esto significa que el discurso se polariza entre quienes apoyan la gestión y quienes son adversarios de la misma, pasando por alto aquellos interlocutores que no han definido una posición.

\section{La reconstrucción de la democracia}

Así como el discurso político es inseparable de la construcción de un adversario, según Bernhardt la definición de un obstáculo discursivo resulta indispensable para otorgarle sentido al relato. En las alocuciones de Néstor Kirchner este tipo de obstáculo se define de distintas formas (el desempleo, el endeudamiento internacional, la decadencia social, la pobreza, las diferencias de desarrollo entre las provincias, la falta de educación y salud), pero básicamente el gran desafío que allí se propone es enfrentar a las elites neoliberales y las políticas que sumergieron al país en una profunda crisis:

Ese modelo económico y social que tuvo un cerebro, que tuvo un nombre y que los argentinos nunca deberemos borrar de nuestra memoria y que espero que también la memoria, justicia y verdad lleguen, se llama José Alfredo Martínez de Hoz.

Lamentablemente, este modelo económico y social no terminó con la dictadura; se derramó hasta fines de los años 90, generando la situación social más aguda que recuerde la historia argentina. (Kirchner, 24 de marzo de 2006)

De la mano de este obstáculo discursivo, se plantea un horizonte utópico (Lechner), es decir, una acción referencial y transformadora que permite efectivamente superar esos obstáculos. De este modo, se articula una iniciativa discursiva que enuncia la reconstrucción de una sociedad devastada como producto de la crisis del 2001, quebrada económicamente por la falta de empleo, el endeudamiento internacional y los altos niveles de inflación, decepcionada y descreída de la dirigencia política y destruida socialmente por la falta de asistencia y protección 
Florencia Daniela Rispolo

de los más postergados. Es sobre esta idea de reconstrucción de la sociedad y la nación, sobre la cual se cimienta la noción de democracia y la idea de un nuevo proyecto de país.

Este concepto de reconstrucción es vertebrador de todo el discurso kirchnerista, ${ }^{6}$ y lo interesante es observar cómo ese horizonte ideal se asocia con una noción de gobierno democrático ligado a lo plural, lo público y el interés colectivo; Kirchner se presenta como un líder, pero uno surgido del pueblo, alejado de los estereotipos tradicionales de políticos, un líder que a fuerza de mucho trabajo y buena fe podrá reconstruir sueños y expectativas de futuro, el abanderado de un nuevo proyecto de país:

No he pedido ni solicitaré cheques en blanco. Vengo, en cambio, a proponerles un sueño: reconstruir nuestra propia identidad como pueblo y como Nación; vengo a proponerles un sueño que es la construcción de la verdad y la justicia; vengo a proponerles un sueño que es el de volver a tener una Argentina con todos y para todos. Les vengo a proponer que recordemos los sueños de nuestros patriotas fundadores y de nuestros abuelos inmigrantes y pioneros, de nuestra generación que puso todo y dejó todo pensando en un país de iguales. Pero sé y estoy convencido de que en esta simbiosis histórica vamos a encontrar el país que nos merecemos los argentinos. (Kirchner, 25 de mayo de 2003)

Es decir, en un contexto social, político y económico marcado por la crisis de $2001,{ }^{7}$ Kirchner logró aglutinar demandas y discursos circulantes para ungirse como el nuevo líder.

Las elecciones en las que se consagra como presidente tampoco estuvieron libres de marchas y contramarchas. En primer lugar, fueron adelantadas para abril de 2003, como producto de la pérdida de legitimidad del gobierno provisional de Eduardo Duhalde y a partir de un hecho en el cual las fuerzas policiales asesinaron a dos militantes en una protesta social. Así mismo, los comicios fueron muy par-

${ }^{6}$ Las referencias al discurso kirchnerista que se realizan en este artículo, sólo implican los discursos emitidos durante la presidencia de Néstor Kirchner (2003-2007)

${ }^{7}$ Desatada los días 19 y 20 de diciembre de 2001 a partir de grandes movilizaciones y protestas populares que provocaron la dimisión del presidente Fernando de la Rúa. 
ticulares, ya que se registró un gran porcentaje de abstenciones y ninguno de los candidatos logró obtener más del $24 \%$ de los votos; esto motivó la realización de una segunda vuelta electoral con los candidatos más votados: Menem (24\%) y Kirchner (22\%). Este habría sido el primer balotaje de la historia Argentina; sin embargo, Carlos Menem decidió retirarse de la segunda vuelta y el Congreso declaró a Néstor Kirchner Presidente de la República Argentina.

Esta situación generó problemas de legitimidad y fortaleza institucional, dado que era el primer presidente en la historia Argentina que accedía al cargo habiendo perdido las elecciones. Estas circunstancias de debilidad fundacional obligaron a Kirchner a buscar apoyo en los distintos sectores políticos. En consecuencia, los primeros discursos impulsaron una democracia plural y conciliadora, que promovía la presencia de distintas voces que acompañaran el mismo objetivo, una nueva forma de hacer política, un nuevo modelo de país:

Es que nos planteamos construir prácticas colectivas de cooperación que superen los discursos individuales de oposición. En los países civilizados con democracias de fuerte intensidad, los adversarios discuten y disienten cooperando. Por eso los convocamos a inventar el futuro. (Kirchner, 25 de mayo de 2003)

Sin embargo, a lo largo de la gestión el panorama fue modificándose: los índices de exclusión y pobreza comenzaron a mejorar, poco a poco comenzó a reactivarse el empleo y se lograron acuerdos con diferentes movimientos sociales que permitieron reducir la conflictividad en las calles. A partir de esos logros, el kirchnerismo comenzó a consolidarse como un espacio político con legitimidad propia, lo cual se reflejó en los discursos. Los pedidos de apoyo a los sectores políticos que aparecían en las primeras comunicaciones fueron diluyéndose y comenzó a aparecer un relato sobre la rectitud y el éxito del camino emprendido:

Y desde el primer discurso que pronunciamos en este recinto, cuando asumí el 25 de mayo de 2003, y mirando los hechos, me resulta evidente que en nuestro caso gobernar, más allá de los aciertos y errores propios de toda tarea humana, perfectible, ha sido una muestra muy fuerte de coherencia. Confrontar lo dicho con lo hecho exige honestidad intelectual por parte de quien lo ha dicho, pero 
Florencia Daniela Rispolo

también por parte de los que se dedican a criticar. Nosotros siempre elegimos ponernos del lado de los intereses de la gente, y en cada solución nos desvelan los resultados que obtendremos en esta lucha por recuperar un país. Así gobernamos y los hechos demuestran que el estado de la Nación ha mejorado ostensiblemente en todos estos años. (Kirchner, o1 de marzo de 2007. 24)

De esta manera, se observa que discursivamente se construyó una noción de democracia ligada a la reconstrucción o renacimiento de la nación, donde los actores privilegiados, y a los que se debía proteger, eran aquellos que, habiendo sufrido los embates de una clase política corrupta, decidían apoyar este nuevo proceso. Un proceso que, según cómo se presentaba en su alocusiones, era liderado por "hombre común" que provenía del pueblo y que se encontraba por fuera de esa clase corrupta que había llevado al país al quiebre (Montero y Vincet).

\section{El contenido de la democracia}

Los discursos no sólo se encuentran atravesados por el contexto histórico, sino también por formaciones sociales e ideológicas que son asimiladas como evidentes por los actores sociales. En otras palabras, el hablante confunde la realidad con el sentido que le atribuye y cree estar en el origen del proceso de significación; esto es lo que Pêcheux llamó Teoría de los dos olvidos.

En este contexto, los discursos ofrecidos por Kirchner se inscriben en una formación ideológica claramente asociada a la izquierda o, más específicamente, al peronismo. Esto significa que en los textos se reconocen reivindicaciones sociales y representaciones de las nociones de clase que detentan estas corrientes políticas:

Para crear una sociedad integrada, con movilidad social y con bienestar es necesario abordar con decisión los temas que constituyen el verdadero núcleo duro de nuestro programa de crecimiento sustentable, producción y empleo con justicia social. (Kirchner, 01 de marzo de 2005. 7)

Así se presentaba al gobierno como el curador de los intereses del pueblo, aquel que lo defendía frente a elites políticas y económicas depredadoras de los intereses 
Un nuevo proyecto de país

colectivos que se oponían a la recuperación del país. De este modo, los discursos configuraron una democracia nacional y popular, que se enfrentaba a los grupos de poder neoliberales que habían dominado en Argentina desde la última dictadura militar.

Se va construyendo un relato donde el pasado y sus protagonistas son los principales enemigos de la patria, mientras que Kirchner es el encargado de torcer el rumbo de una nación en crisis. En este sentido, en el discurso se bosqueja un Estado popular, protector de las instituciones democráticas y de los intereses del pueblo, sobre todo de los miembros más vulnerables. Se propone un Estado fuerte que no sólo tenga capacidad de regular y controlar, sino también de proteger y garantizar los intereses colectivos; un Estado que favorezca un cambio de modelo, un nuevo proyecto:

Dejaremos todo para lograr un país más equitativo, con inclusión social, luchando contra la desocupación, la injusticia y todo lo que nos dejó en su última etapa esta lamentable década del '9o como epílogo de las cosas que nos tocaron vivir. (Kirchner, 24 de marzo de 2004. 2)

Nosotros lo que queremos es que este tiempo de la historia sea recordado como el resurgir de un nuevo amanecer, donde la Argentina empezó a pensar que se podía soñar. Pero como se está saliendo del infierno, y esperamos salir el 10 de diciembre de 2007, hay que salir del infierno primero y ya vendrá el purgatorio, donde con toda la visión estratégica que tenemos discutiremos y debatiremos todas las ideas estratégicas. Pero para salir del infierno, donde se nos cae un argentino y se nos caían millones de argentinos todos los días, había que superar esa situación. (Kirchner, 01 de marzo de 2007. 24)

Esta formación ideológica, en la cual se inscribe, encuentra su expresión más explícita en la apropiación de un determinado interdiscurso, que permite plasmar la ideología con la que se identifica cada enunciador. Dicha noción remite a aquellos elementos que dan cuenta del marco discursivo e ideológico de referencia, en el que se inscriben implícitamente las alocuciones. En palabras de Montero, es el "cuerpo sociohistórico de trazos discursivos previos en los que una secuencia se inscribe, en la medida en que esta secuencia pone necesariamente en juego un discurso-otro, una red de tópicos y filiaciones históricas" (Memorias Discursivas 
Florencia Daniela Rispolo

4). En el caso de los discursos de Kirchner, se observa una importante y muy marcada influencia de la militancia juvenil peronista de los años setenta, caracterizada por la entrega total de la vida del militante a la causa de la organización (Gillespie), es decir, el accionar político se encontraba inspirado por valores y convicciones, por un espíritu idealista. Esto se refleja en varios pasajes de los discursos de Kirchner; por ejemplo:

Nuestra historia, ante cada etapa negra de las muchas que contiene, nos enseña lo importante que resultan aquellos que saben luchar por sus ideales, sus convicciones para poder recuperar los verdaderos valores. Nuestra historia, en su inmensa riqueza, nos está indicando el camino de la recuperación nacional y nos permite la posibilidad de soñar un país mejor que nos contenga a todos. (Kirchner, 20 de junio de 2005)

Fuertemente ligado a este ideario, aparece un interdiscurso propio de los derechos humanos, a partir de la propuesta de reivindicación de los organismos representantes y la condena a los crímenes cometidos durante la última dictadura:

¿Cuál es el compromiso que tienen algunos integrantes de la Justicia? ¿Qué pasa en aquella Cámara de Casación, por dar un ejemplo, donde están parados hace años juicios que deberían estar en marcha? ¿Quiénes son los fiscales de esa Cámara de Casación?

Señores: es hora de que todos, desde donde podamos, hagamos todo el esfuerzo. No estamos invadiendo otro Poder, estamos pidiendo que funcione. Porque les voy a decir una cosa: nosotros no estamos predicando venganza, estamos pidiendo que funcione la Justicia, esa Justicia que nuestros hermanos, nuestros compañeros y nuestros amigos no tuvieron. (Kirchner, 24 de marzo de 2007)

Como parte de la militancia setentista que lo caracteriza y nuevamente en línea con su marco ideológico peronista, Néstor Kirchner inscribe su prédica dentro de una concepción nacional y popular. Así, en los discursos se realiza una interpretación de la historia y la cultura nacional con una perspectiva revolucionaria, americanista y socialista, que propone: la recuperación de la tradición y las formas de conciencia nacionales y populares con el objeto de superar la dependencia económica, política y cultural del imperialismo capitalista; la impugnación de 
una visión eurocéntrica y la postulación de una nación sudamericana, mediante la integración de las repúblicas del continente como imperativo histórico, objetivo estratégico y dimensión necesaria para su plena emancipación, entre otros postulados (Chumbita):

La política social que diseñamos e implementamos desde el inicio de la gestión ha sido concebida como una estrategia central hacia la inclusión, la equidad y la justicia social, superando la visión meramente asistencialista que predominó en el país en las últimas décadas.

Descartamos las visiones fatalistas que dan por hecho la existencia de sectores de la población excluidos en forma permanente. Por el contrario, creemos firmemente que la política social tiene en el centro la promoción de la persona como valor y principio, con la convicción de que una sociedad justa se construye a partir de la equidad. (Kirchner, o1 de marzo de 2006)

[...] Le decimos a todos los hermanos de Latinoamérica que es fundamental seguir consolidando los objetivos de la Patria grande y, junto a los pueblos latinoamericanos, construir una voz fuerte que se levante en todo el mundo para defender los intereses de esta región. (Kirchner, o9 de julio de 2006)

Por tanto, ese nuevo modelo de país y de democracia que se proponía en las distintas comunicaciones, se llena de contenido nacional y popular, de las reivindicaciones de los años 70, de las luchas por los derechos humanos y el castigo a los culpables, de justicia social y de la idea de una "patria grande" y liberada. En otras palabras, el horizonte de reconstrucción de la sociedad implicaba la autonomía nacional, la defensa de la voluntad del pueblo, el crecimiento y desarrollo de aquellos que menos tienen y la reivindicación de las convicciones y valores nacionales.

Finalmente, todo ese contenido nacional-popular convive con una tradición de pensamiento republicana, que refuerza la importancia de las instituciones y el cumplimento de los roles que se le asignan, y donde la relevancia otorgada a las instituciones se reafirma a partir de la mención de próceres como Moreno, San Martín o Belgrano, es decir, de figuras heroicas que fueron protagonistas de la construcción de la patria: 
Florencia Daniela Rispolo

El cambio recién comienza, recién estamos entrando a salir del infierno, recién entramos a visualizar la construcción de una Argentina estratégica como soñara ese gran estratega, el fundador de la bandera, ese gran héroe nacional, ese gran ejemplo que se llamó don Manuel Belgrano y que es un verdadero inspirador junto a San Martín y Mariano Moreno de todas las acciones que nosotros llevamos adelante. Una Argentina integrada a Latinoamérica, una Argentina respetada en el mundo, que no claudique, que no se subordine, que tenga fuerza en sus propias fuerzas es la Argentina que todos nosotros deseamos. (Kirchner, 20 de junio de 2007)

En directa conexión con el horizonte utópico de reconstrucción que plantea el discurso kirchnerista, es posible pensar en una analogía entre los héroes de la patria y la figura de Néstor Kirchner como refundador de una Argentina devastada. Se podría inferir que el discurso pretende relacionar a quienes instituyeron los pilares fundamentales del país y a quien se proponía como el protagonista de la reconstrucción de una Argentina en ruinas.

\section{Los valores de la democracia}

En este contexto, es importante retomar la definición de signo ideológico propuesta por Voloshinov, quien sostiene que las palabras no son neutrales, sino que refractan ideología. Dicho de otro modo, los signos utilizados reflejan la posición social e ideológica del hablante y evidencian las comunidades discursivas en las se insertan los discursos. En este caso, se analizará el signo ideológico vertebrador del corpus seleccionado: el lexema democracia. En primer lugar, se realizará un análisis estadístico, con el fin de rastrear la frecuencia y regularidad con las que aparece la noción de democracia; posteriormente, y en línea con los planteos de Voloshinov, se efectuará un examen que intente dar cuenta del valor semántico que adquiere el concepto.

$\mathrm{Al}$ analizar con una lógica estadística los discursos, se observa que, en un total de diecinueve textos, de los cuales los más extensos fueron pronunciados para el inicio 
Un nuevo proyecto de país

del mandato y la apertura de sesiones parlamentarias, ${ }^{8}$ el lexema democracia ${ }^{9}$ aparece un total de ochenta veces. Esto permite sostener que el concepto se menciona en promedio cuatro veces en cada discurso. Sin embargo, la distribución no se da de manera equitativa; por el contrario, la mayor cantidad de menciones aparece en las sesiones parlamentarias y en los discursos que se refieren a la conmemoración del Día de la Memoria, la Verdad y la Justicia; en tanto que en los discursos de las fechas 25 de mayo, 20 de junio y 9 de julio el concepto casi no aparece. Al mismo tiempo, se observa que más del $65 \%$ de las repeticiones del concepto suceden en los discursos pronunciados durante los últimos dos años de gestión, lo que permite inferir que luego de la segunda mitad del mandato se hizo necesario explicitar el carácter democrático de la gestión.

Independientemente de la cantidad de veces que se menciona la palabra democracia o algún concepto relativo a ella, es necesario mencionar que aparecen a lo largo de los textos otras nociones que forman parte constitutiva de una concepción democrática, tales como: consenso, pluralidad, calidad institucional, federalismo, entre las más importantes. Aquí cabe señalar la diferencia de connotación e intensión que se refleja en cada discurso. Se observa que las referencias a la democracia y sus características en las alocuciones de las fechas patrias se realizan de un modo más emotivo y sentimental, mientras que en la apertura de las sesiones parlamentarias el lenguaje utilizado es más correcto e institucionalizado.

Pero si se analiza el concepto de democracia desde una perspectiva semántica, se observan distintitos valores asociados. El primero de ellos es relativo a la función protectora que debe desarrollar el Estado, valor asociado directamente a la reivindicación de la legalidad del régimen, en oposición a la experiencia acontecida en el último proceso militar. En otras palabras, los discursos vinculan la democracia con aquella función proteccionista de la vida que mencionaba Hobbes cuando daba los fundamentos de la constitución de ese gran Leviatán que permitiría la vida en sociedad. Por ejemplo:

\footnotetext{
${ }^{8}$ Los discursos emitidos para las fechas patrias no superan las tres o cuatro hojas de extensión.

${ }^{9}$ Los conceptos asociados a democracia que aparecen en los textos son: democrática/o, democratización y democratizar.
} 
Florencia Daniela Rispolo

Entre los fundamentales e insustituibles roles del Estado ubicamos los de ejercer el monopolio de la fuerza y combatir cualquier forma de impunidad del delito, para lograr seguridad ciudadana y justicia en una sociedad democrática en la que se respeten los derechos humanos. (Kirchner, 25 de mayo de 2003)

Un segundo valor asociado a la democracia es la institucionalidad. Éste se liga directamente al clima de apatía y desinterés ciudadano frente a las cuestiones políticas, producto de la fuerte crisis que atravesaba el país desde 2001. A partir del discurso se intenta proponer un nuevo proyecto de Estado, un Estado sólido, legítimo y respetuoso de los roles que se les asignan a las instituciones:

Hemos colaborado, con la Constitución Nacional como marco, en una profunda renovación de la Corte Suprema de Justicia que era reclamada por la sociedad; hemos instaurando[sic], autolimitando facultades propias, métodos de selección con participación y transparencia como nunca en la historia del país, y estamos produciendo la más gigantesca cobertura de vacantes en el Poder Judicial a que haya habido lugar en la historia de nuestra democracia, con similares métodos. (Kirchner, 01 de marzo de 2005)

Finalmente, una tercera dimensión que se advierte en el signo de democracia tiene que ver con el progreso social. Este valor debe comprenderse dentro de la formación ideológica peronista en la que se inscriben los discursos analizados. De este modo, se le otorga al concepto un contenido de crecimiento y desarrollo social, de defensa de los sectores más vulnerables:

Tenemos la obligación y el desafío de consolidar un país integrado y justo, en el que todas las regiones tengan las mismas posibilidades, un país capaz de destacarse por la calidad de su producción, con las reglas claras, con empresarios innovadores y creativos, conectados al mundo, pero defendiendo dignamente sus intereses; un país donde los hijos puedan vivir mejor que sus padres, sobre la base de la igualdad de oportunidades y el esfuerzo propio; un país que se oponga a las falsas dicotomías que generen inútiles y desgastantes enfrentamientos, una Argentina en que no valga la pena querer o buscar el fracaso del otro y donde el desafío sea la continua superación. 
Un nuevo proyecto de país

Hemos concretado, en el tiempo en que se nos ha responsabilizado con la iniciativa política, con la casi totalidad de planes y proyectos - y aún más-con los que fuimos a la lucha electoral. Juzgados desde la perspectiva del bien común, el funcionamiento pleno del estado de derecho, la vigencia de una efectiva democracia, la correcta gestión de los asuntos de Gobierno, el ejercicio del poder político a favor del bienestar del pueblo, sentimos que hemos cumplido. (Kirchner, 01 de marzo de 2007)

Así, cabe reiterar que las nociones de democracia y de nuevo proyecto de país, se construyen desde una visión defensora de los intereses populares, protectora de los derechos de los ciudadanos y partidaria de un Estado con instituciones robustas y confiables.

Es interesante señalar que la interpretación del concepto de democracia que realiza el discurso kirchnerista es representativa de una determinada formación discursiva, ${ }^{10}$ por lo tanto esa definición se enfrenta a índices de valor contrapuestos y expresados por formaciones discursivas antagónicas; esto es lo que Maingueneau denomina inter-incomprensión constitutiva. En otras palabras, parte de la delimitación de los signos ideológicos utilizados por una formación discursiva, están determinados por las definiciones que proveen las formaciones discursivas rivales. Así, el discurso kirchnerista que reivindica los postulados del progresismo, el peronismo, los derechos humanos, lo nacional-popular y lo colectivo, se enfrenta directamente a formaciones discursivas propias del neoliberalismo y la derecha autoritarita:

Estas visones neoliberales y de derecha sostienen que la meta de cualquier gobierno debe ser monetaria, para lo cual es necesaria una disciplina presupuestaria que contenga el gasto social, que restructure la tasa "natural" de desempleo y elabore reformas fiscales que permitan incentivar a los agentes económicos; de esa forma una nueva y saludable desigualdad dinamizaría las economías (Anderson). En Argentina esto se tradujo en la defensa a ultranza de las virtudes de mercado y los beneficios distribucionistas que, supuestamente, traía su libre desenvolvimiento, la apertura irrestricta de los mercados, la aplicación de una política

\footnotetext{
${ }^{10}$ Este concepto hace referencia a las regularidades entre objetos, tipos de enunciación, conceptos o elecciones temáticas, que aparecen en un cierto número de enunciados.
} 
Florencia Daniela Rispolo

cambiaria fija atada al dólar, la aplicación de políticas establecidas por organismos internacionales y la toma de deuda internacional. Las consecuencias de estas políticas provocaron la ampliación de las fronteras de la exclusión, un creciente empobrecimiento y la descolectivización de las clases populares (Svampa).

En oposición a estas alternativas políticas y su formación discursiva, se construye el discurso de Néstor Kirchner en torno a la democracia:

A comienzos de los 80, se puso el acento en el mantenimiento de las reglas de la democracia y los objetivos planteados no iban más allá del aseguramiento de la subordinación real de las Fuerzas Armadas al poder político. La medida del éxito de aquella etapa histórica no exigía ir más allá de la preservación del Estado de derecho, la continuidad de las autoridades elegidas por el pueblo. Así se destacaba como avance significativo y prueba de mayor eficacia la simple alternancia de distintos partidos en el poder.

En la década de los 90, la exigencia sumó la necesidad de la obtención de avances en materia económica, en particular, en materia de control de la inflación. La medida del éxito de esa política, la daba las ganancias de los grupos más concentrados de la economía, la ausencia de corridas bursátiles y la magnitud de las inversiones especulativas sin que importara la consolidación de la pobreza y la condena a millones de argentinos a la exclusión social, la fragmentación nacional y el enorme e interminable endeudamiento externo. (Kirchner, 25 de marzo de 2003)

De este modo, los discursos plantean una ruptura radical frente a las concepciones de democracia y Estado que se encontraban vigentes, se construye discursivamente la posibilidad un nuevo proyecto de país. Tal como se mencionaba anteriormente, esta toma de posición fue producto de un contexto signado por la apatía y desinterés político, pero a la vez plagado de fuertes demandas de mejoramiento social y económico. Frente a ello, el discurso kirchnerista propone un relato transformador, de un nuevo proyecto de país que permitiría salir del "infierno" provocado por mezquinos intereses corporativos, de la mano de Kirchner como el principal protagonista de esa historia. 
Un nuevo proyecto de país

\section{Recapitulaciones}

A partir del análisis del corpus discursivo seleccionado, ha sido posible extraer algunas reflexiones interesantes sobre las alocuciones del exmandatario Néstor Kirchner. A continuación, se recuperarán algunos de esos aportes a fin de intentar reflejar la construcción en torno al concepto de democracia que se sostuvo durante la primera etapa kirchnerista.

En primer lugar, si se toma como punto de partida el análisis estadístico alusivo al uso del concepto de democracia, es posible observar que no hay una referencia recurrente y explicita a esta noción. Aunque no siempre el concepto se subsume bajo la etiqueta de "democracia", sino que existen otras nociones que también pueden asociarse a la idea democrática, tales como: consenso, pluralidad, calidad institucional, federalismo, entre otros.

De este modo, a partir de una mirada más amplia y superadora, que traspasa el campo de la estadística y se apoya en los aspectos semánticos, es posible sostener que la noción de democracia aparece implícita o explícitamente en todo el corpus discursivo. Mientras en los discursos pronunciados en las efemérides nacionales lo democrático se encuentra ligado a lo emotivo y al sentimiento patriótico, en las alocuciones pronunciadas en la apertura de sesiones parlamentarias las referencias resultan más correctas y contenidas. No obstante, en ambos casos subyace una construcción de democracia ligada al pueblo y a la defensa de los intereses colectivos.

En este punto, resulta fundamental recuperar las reflexiones sobre los tres valores asociados a la democracia: protección, institucionalidad y progreso. Cada uno de éstos, definen a la perfección la noción de Estado democrático que se alimenta desde los discursos. Frente a una Argentina quebrada y en crisis, que reclamaba soluciones inmediatas y alivio económico y social, se diagramó un discurso proteccionista que enfrentara el estremecimiento de la sociedad frente a las condiciones de inseguridad. Al mismo tiempo, se sostuvo que era necesario salvaguardar los intereses del pueblo y de los más desfavorecidos; en otras palabras, se reivindicaba la noción progreso social, que había sido olvidada durante décadas por los proyectos defensores de intereses predatorios del Estado. Y finalmente se sostenía la importancia de resguardar las instituciones, frente a una clase política 
Florencia Daniela Rispolo

corrupta que había defraudado y empujado al ciudadano al desinterés y apatía política.

De este modo, el discurso presentó a la gestión como un "Nuevo proyecto" que cambiaría el rumbo del país; un proyecto dirigido a priorizar al pueblo, la nación y sus intereses, a integrar a aquellos que hasta el momento se encontraban excluidos, a transformar un Estado corrupto en un Estado sólido y recto. En otras palabras, se bosquejó un discurso en donde se llama a construir una democracia equitativa, que ofrezca igualdad de oportunidades y protección al pueblo; se trazó como horizonte la reconstrucción económica, social y política del país, que modificaría el relato de la historia.

En esta narración de reconstrucción y cambio de rumbo, Kirchner es señalado como el protagonista, el abanderado de ese proyecto transformador. Se construye la figura de un hombre con convicciones y sueños, heredero de la lucha democrática de los setenta que había resistido los embates de la dictadura; Kirchner era el líder que llevaría al triunfo los intereses del pueblo argentino.

\section{Florencia Daniela Rispolo}

Lic. en Ciencia Política. Becaria de Doctorado del Consejo Nacional de Investigaciones Científicas y Técnicas en el Instituto de Humanidades y Ciencias Sociales del Litoral (inucso-UnL-Conicet). Jefe de Trabajos Prácticos de Introducción a las Ciencias Sociales, carreras de Contador Público Nacional, Lic. en Economía y Lic. en administración, de la Universidad Nacional del Litoral. Miembro investigadora del CAI+D "Orígenes de la polarización social y política en la Argentina reciente. Aproximaciones desde la política nacional y provincial (2003-2011)", Departamento de Sociología, Facultad de Humanidades y Ciencias, Universidad Nacional del Litoral. Santa Fe, Argentina. 
Un nuevo proyecto de país

\section{Obras citadas}

Amadeo, Belén y Adriana Amado. "El periodismo frente a la comunicación gubernamental: condicionamientos oficiales a la tarea periodística". Opera 23 (2013): 41-58. Web. < https://revistas.uexternado.edu.co/index.php/opera/article/view/3764>

Amado, Adriana. "La épica no es fiesta. [El drama como estilo de comunicación del gobierno argentino]". Perspectivas 8 (2013). < http://library.fes.de/pdf-files/bueros/la-comunicacion/14242.pdf>

Anderson, Perry. "Balance del neoliberalismo: lecciones para la izquierda". Procesos. Revista ecuatoriana de historia 11 (1997): 11-127. Web. <http://repositorio.uasb. edu.ec/bitstream/10644/1350/1/RP-11-Documentos.pdf>

Annunziata, R. "El candidato es el proyecto: la construcción de la narrativa kirchnerista”. Comunicación gubernamental en acción: narrativas presidenciales y mitos de gobierno. Ed. M. Riorda \& O. Rincón. Buenos Aires: Biblos, 2016. 111-128. Impreso.

Barros, Sebastián. "Notas sobre los orígenes del discurso kirchnerista". Comp. Balsa, Javier. Discurso, política y acumulación en el kirchnerismo. Buenos aires: Centro Cultural de la Cooperación Floreal Gorini y Universidad Nacional de Quilmes, 2013. 37-49. Impreso.

Bernhardt, Florencia. "La conceptualización del obstáculo en el discurso político". (Publicación interna). Buenos Aires: Universidad de Ciencias Empresariales y Sociales. 2001. Web. <http://dspace.uces.edu.ar:8180/dspace/bitstream/handle/123456789/2294/Conceptualizaci\%C3\%B3n-del-obst\%c3\%A1 culo.pdf?sequence $=1>$

Biglieri, Paula y Gloria Perelló. En el nombre del pueblo. La emergencia del populismo kirchnerista. Buenos Aires: UNSAM, 2017. Impreso.

Califano, Bernadette. "Medios y políticas de comunicación en Argentina bajo el gobierno de Néstor Kirchner 2003-2007". Tesis publicada. Buenos Aires: Tesina de grado de la Universidad de Buenos Aires, 2009. Impreso. 
Florencia Daniela Rispolo

Canel, M. J., \& Sanders, K. "Is It Enough to Be Strategic? Comparing and Defining Professional Government Communication across Disciplinary Fields and between Countries". Comparing Political Communication across Time and Space. New Studies in an Emerging Field. Ed. M. J. Canel \& K. Voltmer. London: Palgrave Macmillan, 2014. 98-116. Web.

Cheresky, Isidoro. "Cambio de rumbo y recomposición política en Argentina - Néstor Kirchner cumple un año de gobierno". La Chronique des Amériques 17 (2004): 1-8. Web. <https://core.ac.uk/download/pdf/96125417.pdf>

Chumbita, Hugo. "Patria y revolución: la corriente nacionalista de izquierda". $E l$ pensamiento alternativo en la Argentina del siglo xx: obrerismo, vanguardia, justicia social (1930-1960) Ed. H. E. Biagini \& A. A. Roig. Vol. II. Buenos Aires: Biblos, 2006. 77-100. Impreso.

Eagleton, Terry. Ideología. Una introducción. Barcelona: Paidós, 1997. Impreso.

Garzón Rogé, Mariana. "La construcción imaginaria de los límites políticos a través de las personas gramaticales y los enunciados polifónicos: el caso del discurso de Néstor Kirchner". Anclaje 13 (2009): 91-113. Web. < https://dialnet.unirioja. es/servlet/articulo? codigo $=4794274>$

Gillespie, Richard. Los soldados de Perón. Los montoneros. Buenos Aires: Grijalbo, 1987. Impreso.

Hobbes, Thomas. Leviatán, o La materia, forma y poder de una república eclesiástica y civil. México: Fondo de Cultura Económica, 1651. Impreso.

Kitzberger, Philip. "La madre de todas las batallas". Coords. Malamud, Andrés y Miguel de Luca. La politica en tiempos de los Kirchner. Buenos Aires: Eudeba, 2012. 179-192. Impreso.

Lechner, R. Textos Escogidos Vol I-II. Santiago de Chile: LOM, 2006. Impreso.

Maingueneau, Dominique. Termos-chave da Análise do Discurso. Belo Horizonte: UFMG, 1998. Impreso.

Martínez, Fabiana. "Aproximación a algunos tópicos del 'discurso kirchnerista". Comp. Javier Balsa. Discurso, política y acumulación en el kirchnerismo. Buenos 
Un nuevo proyecto de país

Aires: Universidad Nacional de Quilmes y Centro Cultural de la Cooperación Floreal Gorini, 2013. 52-66. Impreso

Mastrini, Guillermo. "Al final del período. Los límites del progresismo: políticas de comunicación en Argentina durante el gobierno de Néstor Kirchner". Apunte de la cátedra de "Políticas y planificación de la comunicación". Carrera de Ciencia de la Comunicación de la Facultad de Ciencias Sociales de la Universidad de Buenos Aires, 2014. Impreso

Montero, Ana S. Memorias discursivas de los '70 y ethos militante en la retórica kirchnerista (2003- 2006). Buenos Aires, Argentina: $4^{\circ}$ Jornadas de Jóvenes Investigadores del Instituto Gino Germani. 2007. Web. <https://www.aacademica.org/ooo-024/106.pdf>

Montero, Ana S. "Puesta en escena, destinación y contradestinación en el discurso kirchnerista (Argentina, 2003-2007)". Discurso y Sociedad 3.2 (2009): 316- 347. Web. <https://pdfs.semanticscholar.org/c818/b56c48cd29906ed775a7c6effa31566do8a7.pdf $>$

Montero, A. S. y Vincent L. 'Del 'peronismo impuro' al 'kirchnerismo puro': la construcción de una nueva identidad política durante la presidencia del Néstor Kirchner en Argentina (2003-2007)". PostData. Revista de reflexión y análisis político 18.1 (2010): 123-157. Web. <https://ri.conicet.gov.ar/bitstream/handle/11336/9133/v18n1a05.pdf? sequence $=2$ \&isAllowed $=y>$

Muñoz, María Antonia y Martín Retamozo. "Hegemonía y discurso en la Argentina contemporánea: Efectos políticos de los usos de 'pueblo' en la retórica de Néstor Kirchner". Perfiles latinoamericanos 31.16 (2008): 121-149. Web. $<$ http://www. memoria.fahce.unlp.edu.ar/library? $\mathrm{a}=\mathrm{d} \& \mathrm{c}=\operatorname{arti} \& \mathrm{~d}=J \mathrm{pr} 8586>$

Pêcheux, Michel. Hacia el análisis automático del discurso. Madrid: Gredos, 1978. Impreso.

Retamozo, Martín. "Discurso y lógicas políticas en clave K. Movimientos, populismo y hegemonía en la Argentina”. Comp. Javier Balsa. Discurso, política y acumulación en el kirchnerismo. Buenos Aires: Universidad Nacional de QuilmesCentro Cultural de la Cooperación Floreal Gorini, 2013. 143-156. Impreso 
Florencia Daniela Rispolo

Retamozo, Martín. "Populismo en América Latina: desde la teoría hacia el análisis político. Discurso, sujeto e inclusión en el caso argentino". Colombia Internacional 82 (2014): 221-258. Web. < http://dx.doi.org/10.7440/colombiaint82.2014.09>

Riorda, Mario. "Mitos y política: estilos comunicativos de los gobernadores cordobeses (1983-2003)". Estudios 15 (2004):119-143. Web. <https://revistas.unc.edu. ar/index.php/restudios/article/view/13540>

Riorda, Mario. "Hacia un modelo de comunicación gubernamental para el consenso". Revista del foro iberoamericano sobre estrategias de comunicación 2.4 (2006). Web. <http://www.cienciared.com.ar/ra/usr/9/257/fiseco4riorda.pdf>

Riorda, Mario. "Los mitos de gobierno. Una visión desde la comunicación gubernamental". Hologramática 3.4 (2006): 21-45. Web. <http://www.cienciared.com. ar/ra/usr/3/189/hologramatica4_v2pp21_45.pdf $>$

Riorda, Mario. "Gobierno bien pero comunico mal: análisis de las rutinas de la comunicación gubernamental". Revista del CLAD-Reforma y democracia (2008). Web. <http://old.clad.org/portal/publicaciones-del-clad/revista-clad-reforma-democracia/articulos/o40-febrero-2008/riorda>

Riorda, Mario. "La comunicación gubernamental como comunicación gubernamental”. Politai, 2.3 (2011): 96-111. Web. < http://revistas.pucp.edu.pe/index. php/politai/article/view/13956>

Svampa, Maristella. "Argentina, una década después. Del 'que se vayan todos' a una exacerbación de lo nacional-popular". Nueva Sociedad 235 (2011). Web. <https:// nuso.org/media/articles/downloads/3794_1.pdf>

Verón, Eliseo. "La palabra adversativa". El discurso político. Lenguajes y acontecimientos. Ed. E. Verón, L. Arfuch, M. M. Chirico, E. De Ipola, N. Goldman, M. I. González Bombal, \& O. Landi. Buenos Aires: Hachette, 1985. Impreso.

Verón, Eliseo. La semiosis social. Barcelona: Gedisa, 1993. Impreso

Voloshinov, Valentín. N. El marxismo y la filosofía del lenguaje. Los principales problemas del método sociológico en la ciencia del lenguaje. Madrid: Alianza, 1992. Impreso. 
Un nuevo proyecto de país

\section{Discursos consultados}

Kirchner, Néstor. Discurso de Inicio de Mandato como Presidente de la República Argentina. Buenos Aires, Argentina. 25 de mayo de 2003.

Kirchner, Néstor. Discurso por la conmemoración del Día de la Bandera. Rosario, Argentina. 20 de junio de 2003.

Kirchner, Néstor. Discurso de apertura de sesiones parlamentarias. Buenos Aires, Argentina. 1 de marzo de 2004.

Kirchner, Néstor. Discurso por el Día de la Memoria, la Verdad y la Justicia. Buenos Aires, Argentina. 24 de marzo de 2004.

Kirchner, Néstor. Discurso de apertura de sesiones parlamentarias. Buenos Aires, Argentina. 1 de marzo de 2005.

Kirchner, Néstor. Discurso en el $195^{\circ}$ aniversario de la conmemoración de la Revolución de Mayo. Buenos Aires, Argentina. Santiago del Estero, Argentina. 25 de mayo de 2005.

Kirchner, Néstor. Discurso por la conmemoración del $189^{\circ}$ aniversario de la Declaración de Independencia. Tucumán, Argentina. 9 de julio de 2005.

Kirchner, Néstor. Discurso por la conmemoración del Día de la Bandera. Rosario, Argentina. 20 de junio de 2005.

Kirchner, Néstor. Discurso de apertura de sesiones parlamentarias. Buenos Aires, Argentina. 1 de marzo de 2006.

Kirchner, Néstor. Discurso en el $196^{\circ}$ aniversario de la conmemoración de la Revolución de Mayo. Buenos Aires, Argentina. 25 de mayo de 2006.

Kirchner, Néstor. Discurso por el Día de la Memoria, la Verdad y la Justicia. Buenos Aires, Argentina. 24 de marzo de 2006.

Kirchner, Néstor. Discurso por la conmemoración del $190^{\circ}$ aniversario de la Declaración de Independencia. Tucumán, Argentina. 9 de julio de 2006.

Kirchner, Néstor. Discurso de apertura de sesiones parlamentarias. Buenos Aires, Argentina. 1 de marzo de 2007.

Kirchner, Néstor. Discurso por el Día de la Memoria, la Verdad y la Justicia. Córdoba, Argentina. 24 de marzo de 2007.

Kirchner, Néstor. Discurso por la conmemoración del Día de la Bandera. Rosario, Argentina. 20 de junio de 2007. 